\title{
Knowledge Management and BIM Technology in Construction Project Management
}

\author{
Tomáš Mandičák ${ }^{1}$ and Peter Mésároš ${ }^{2}$
}

1 Technical University of Košice, Košice, Slovakia, tomas.mandficak@tuke.sk

2 Technical University of Košice, Košice, Slovakia, peter.mesaros@tuke.sk

\begin{abstract}
Knowledge systems and knowledge technologies are an important tool for resource efficiency in the management of construction projects. The exploitation of the knowledge systems is essential throughout the construction period, starting with designing and ending the building management. BIM technology represents another progressive technology in the management of construction projects. Last decades, it's a lot of information and assumption about the connection of BIM technology and knowledge-based technology in constriction project management. This research discusses the issue of knowledge management and uses BIM technology in constriction project management. The main aim of the research is to analyze the level of exploitation of BIM technology and knowledge-based technology in construction project management in selected countries in Europe.
\end{abstract}

(c) 2020 The Authors. Published by Budapest University of Technology and Economics \& Diamond Congress Ltd Peer-review under responsibility of the Scientific Committee of the Creative Construction Conference 2020.

Keywords: knowledge management, BIM technology, construction project management

\section{Introduction}

Progressive technologies push the possibilities of working in every industry. Architecture, engineering, and construction (AEC) is no exception. The importance of the implementation of information and communication technologies has probably never been more important than it is now [1]. On the one hand, it is the current situation that has also affected the construction sector. On the other hand, there is a longterm need to manage processes in construction projects and automate management activities [2]. Already in the last century, there has been an effort to automate some processes in the management of construction projects and thus achieve efficiency. Innovative technologies in the management of construction projects are often the impetus for starting automated processes, which has a positive impact on the efficiency of construction projects.

The present time places great emphasis on information. The information constitutes valuable assets of the company [3]. Based on timely and relevant information, it is also possible to achieve a high degree of success in the management of construction projects. The need for information is indisputable. This is stated by several researchers dealing in The Knowledge management field [4]. Effective tools for managing and working with information must be applied as far as possible at every stage of the construction project. Various information systems and decision support tools work with large amounts of data. After processing, they often have great potential for making the right decisions. This information is translated into the knowledge of managers, which leads to the right decisions. These decisions often affect the outcome and success of a construction project. When solving a successful solution of construction projects, it is necessary to use the human side for the needs, which is always at the input and finally the output of the process. 
Knowledge technologies managed by the human factor are a potential tool that in many cases can define the outcome of construction projects. This means the need to find the right technologies and people who can achieve a synergistic effect [5]. This all leads to another goal, which is closely related to the use of knowledge technologies and BIM technologies, and that is the possibility of education [6]. The need for education in the field of knowledge technologies and BIM technologies is indisputable and several researchers are addressing this [6], [7].

\section{Problem statement}

Knowledge management and project management theory are important to participate in a project [8]. Despite this fact, the development and introduction of digital skills usually only answer to the current problem. There are only a few cases when it is supported by a long-term strategy [9]. Knowledge management (as well as KM) is now a usual concept in the architecture, engineering, construction (AEC) industry, and the effective management of project knowledge, it is acknowledged, is necessary for improved performance. KM deals with the organizational optimization of knowledge through the use of various technologies, tools, and processes to achieve set goals [10]. In the case of the AEC industry, these goals include improved efficiency and innovation in project delivery. $\mathrm{KM}$ is also seen as a means to prevent the 'reinvention-of-the-wheel' for every new project [11].

A reached of what knowledge is top to its effective management. E.g. knowledge is considered to be interchangeable with information, then the focus tends to be on the management of information systems as a proxy for knowledge management [12]. However, the various definitions of knowledge suggest that it is much more than information. According to some authors, knowledge can be defined as a dynamic human process of justifying personal belief toward the "truth" (i.e. a justified true belief). Knowledge has also been defined as 'know-why, know-how, or an intangible economic resource from which future revenues will be derived [13]. Attempts to distinguish between data, information, and knowledge have also geared towards the understanding of the latter [14]. However, it is necessary to view knowledge based on its final use and/or based on the context of its use. This underscores the fact that knowledge can be viewed as a component of a task performing system. That is a state of that system which warrants task completion, and the future repetition of this task. The lack of this component implies a failure when completing a task. If this lack is sustained over time, it means that this system ceases to exist. Knowledge is built from data, which is first processed into information (i.e. relevant associations and patterns). Information becomes knowledge when it enters the system and when it is validated (collectively or individually) as a valid, relevant, and useful piece of knowledge to implement in the system [15].

Due to the new threats and challenges faced by the construction industry today, construction enterprises have to accept challenges and new solutions in order to remain ahead of the competition. Knowledge has been identified to be a significant organizational resource, which if used effectively can provide a competitive advantage. A lot of emphasis is being put on how to identify, capture, and share knowledge in today's organizations. It has been argued over the years that due to the fragmented nature of the construction industry and ad-hoc nature of the construction projects, capture and reuse of valuable knowledge gathered during a construction project pose a challenge [16]. Last year there has been no structured approach to learning from construction projects once they are completed. Actually, the construction project management is adapting concepts of tacit and explicit knowledge management to improve the situation. Generally, top managers assume that professionals in companies already possess tacit knowledge and experience for specific types of projects. Such knowledge is extremely important to organizations because, once a project is completed, professionals tend to forget it and start something new. Therefore, knowledge multifield utilization is a key factor in productively executing a construction project [17].

Knowledge Management (KM) has become an important term in the construction industry. Knowledge management involves many activities like creating, securing, capturing, coordinating, combining, retrieving, and distributing knowledge. Most know-what, know-how, and experience exist only in the minds of individual participants during the construction phase of construction projects. The knowledge can be reused and shared among the engineers and experts involved who participate in projects in order to 
improve the construction process and reduce the time and cost of solving problems. Sharing and reusing knowledge depends on acquiring and preserving both tacit knowledge and explicit knowledge as the property of a corporation. Effectively using information and web technologies during the construction phase of a project enables knowledge to be captured and managed to the benefit of future projects [18]. Construction Project Management (CPM) has a strong tool trough knowledge technology and BIM tools. BIM technology is valuable in each stage of the construction project. In the context of knowledge management, it is a solution for construction project participants (investors, designers, contractors, and other participants). Knowledge technology gives some advantages for construction project management. It's the first step to the automation of processes and some activities. Connection of BIM technology and knowledge technology can be helpful in many routine activities and it's possible to manage all information. The problem statement is actually the rate of exploitation of these technologies in construction project management. The level of exploitation in other countries is not different. It depends on many factors, but specifics and many characteristics of the construction market and industry are very similar.

\section{Methodology and research sample}

\subsection{Hypothesis and research aim}

Construction Project Management is a difficult process and its success depends on many factors. Enterprise size is one of them. It's an assumption, that the exploitation level is different in each country. The subject of research were three countries in the middle of Europe. The main aim of the research is to analyse the level of exploitation of BIM technology and knowledge-based technology in construction project management in selected countries in Europe. The main hypothesis was set: The exploitation level in selected countries is not different. The research was done in Slovakia, Poland, and the Czech Republic. The research sample includes the main participants of construction projects, which means investors, designers, constructors, and sub-constructors. According to enterprise size, the research was done on the SMEs (small and medium-sized enterprises) and large companies. The research sample is detailed described in Tab. 1. and Tab. 2.

Table 1. Research Sample according to size of construction enterprises

\begin{tabular}{lll}
\hline An example of a column heading & SMEs & Large \\
& & Companies \\
\hline Slovakia & 51 & 4 \\
Poland & 47 & 12 \\
Czech Republic & 58 & 7 \\
\hline
\end{tabular}

Table 2. Research Sample according to Participants of Construction Projects

\begin{tabular}{lllll}
\hline An example of a column heading & Investors & Designers & Contractors & Sub-Contractors \\
\hline Slovakia & 21 & 11 & 8 & 15 \\
Poland & 14 & 13 & 15 & 17 \\
Czech Republic & 13 & 21 & 18 & 13 \\
\hline
\end{tabular}

\subsection{Research steps, data collection and processing}

After the determination of the final hypothesis and the established research problem and the goal of the research, the phase of data collection followed and last but not least the evaluation of data on the basis of selected statistical methods.

To confirm our hypotheses about mean ranks, the Mann-Whitney $U$ test was used. It is nonparametric alternative to t-test and it does not assume any assumptions related to the distribution of scores [20]. This test is used to compare two sample means that come from the same population and used to test whether two sample means are equal or not. It gives the most accurate estimates of significance, especially when sample sizes are small. 
Equation (1) for calculation of the Mann-Whitney U:

$$
U=n_{1} n_{2}+\frac{n_{2}\left(n_{2}+1\right)}{2}-\sum_{i=n_{1}+1}^{n_{2}} R_{i}
$$

where

$$
\begin{aligned}
& U=\text { Mann-Whitney } U \text { test } \\
& n_{1}=\text { sample size one } \\
& n_{2}=\text { sample size two } \\
& R_{i}=\text { rank of the sample size }
\end{aligned}
$$

\section{Results and discussion}

Computation of this test was done in MATLAB. We have tested samples individually and also differences between each measurement (Slovakia, Poland, and the Czech Republic) were tested. These results were obtained:

Table 3. Results of Research Sample distribution

\begin{tabular}{llll}
\hline An example of a column heading & Slovakia & Poland & Czech Republic \\
\hline Mean & 2.876 & 3.125 & 2.987 \\
Standard Deviation & & & \\
Number of respondents & 55 & 59 & 65 \\
Skewness & 0.928 & -0.023 & 0.972 \\
Kurtosis & 0.498 & -1.097 & 0.765 \\
& & & \\
\hline
\end{tabular}

According results, samples were not equal. In addition, mean of ranks were numerically compared so According to results, samples were not equal. Also, the mean of ranks was numerically compared so we could assume that really and results were different for each country's results.

Generally, the exploitation level of BIM and knowledge technology for each country divided according to participants od construction projects a Mann-Whitney ranking are described in Tab. 4.

Table 3. Results of MU test

\begin{tabular}{llll}
\hline An example of a column heading & Slovakia & Poland & Czech Republic \\
\hline Impact rate & 2.88 & 3.22 & 3.00 \\
Number of Valid responses & 0.928 & -0.023 & 0.972 \\
Code & 1 & 2 & 3 \\
$\mathrm{p}$ & & & 0.1189 \\
\hline
\end{tabular}

Please make sure that you use as much as possible normal fonts in your documents. Special fonts, such as fonts used in the Far East (Japanese, Chinese, Korean, etc.) may cause problems during processing. To avoid unnecessary errors, you are strongly advised to use the 'spellchecker' function of MS Word. Follow this order when typing manuscripts: Title, Authors, Affiliations, Abstract, Keywords, Main text (including figures and tables), Acknowledgements, References, Appendix. Collate acknowledgments in a separate section at the end of the article and do not include them on the title page, as a footnote to the title or otherwise.

Based on detailed results and testing, these results and considerations can be presented. The basic premise was the consideration that the construction market in Central Europe and thus also in the V4 countries are very interconnected and similar. The conditions in construction are similar. For example, the following facts can be considered as the most basic common features: 
- The greatest construction boom is in capital cities and large cities, or its immediate surroundings;

- Infrastructure and road construction are largely under government control and planning;

- For the implementation of large projects, it is necessary to have experience and competitions are usually won by large companies, which represent a guarantee and ability to complete the project;

- SMEs make up $80 \%$ or more of enterprises;

- The standard of living of the population is approximately at the same level.

Of course, each construction industry has its specifics and small differences, which, however, do not represent a diametrically different situation with general characteristics. From this point of view as well, it was assumed that these countries have the same level of use of BIM and knowledge technologies. These results also indicate the results of the survey. However, in the exact measurement, several facts need to be pointed out. The results show that the assumption that individual countries have the same or similar degree of use of BIM technologies and knowledge technologies is correct. The results of the survey do point to this trend. The spacing of the difference was less than 0.3 which represents the minimum deviations.

On the other hand, the Mann-Whitney test did not confirm this at the level of alpha significance. P-value has reached 0.1189 and these results also point to the closeness of the statement that the results are similar, but the statistical test did not directly confirm this and therefore, from an exact point of view, the established hypothesis cannot be accepted. We can discuss why, although all indications point to similar use of technology, this has not been confirmed by tests. However, as already mentioned, these countries also have certain specifics for the market and the conditions of their country. This means that even though the legislation is similar, it is not the same. On the other hand, consumer psychology is also an important aspect. The requirements of investors are a little different in each country.

\section{Conclusion}

The issue of using BIM and knowledge technologies have recently become very popular and important. It is necessary to analyse and compare the degree of use of these technologies in individual countries. This research was aimed at comparing results in countries that have many similar features. This was the main assumption that the rate of use of these technologies will not be different. This means that their range will not be greater than 0.5 points and at the same time this will be confirmed by a statistical test. The results that point to this point to a trend. The initial assumption and reasoning were relatively correct. Respectively, the results point to the given trend. However, the exact statistical measurement did not unequivocally confirm this and therefore the established hypothesis cannot be accepted exactly. In terms of future research, it is important to obtain data for another V4 country and extend this research to Hungary and then compare it. It would also be interesting to make a comparison between different sizes of companies, where, for example, only large companies in individual countries would be compared with large ones in another country. These are interesting considerations and space to continue to address this topic.

\section{Acknowledgements}

This work was supported by the Slovak Research and Development Agency under the contract no. APVV17- 0549.

The paper presents a partial research results of project VEGA 1/0828/17 "Research and application of knowledge-based systems for modeling cost and economic parameters in Building Information Modeling"

\section{References}

[1] J. Dugas, A. Seňová, B. Kršák, B. Fferencz, "Implementation of business intelligence tools in companies", New trends in process control and production management: proceedings of the international conference on marketing management, trade, financial and social aspects of business. - Leiden (Netherlands) : Balkema pp. 93-95, 2018 [print]. - ISBN 978-1-138-05885-9

[2] E. Radziszewska-Zielina et al., "Managing Information Flow in Self-Organising Networks of Communication Between Construction Project Participants", Archives of |civil Engineering, Vol. 65., No. 2, 2019, https://doi.org/10.2478/ace-2019-0024

[3] M. Balog et al., "Productivity Fluid Management as a Tool for Saving Money in Manufacturing", TEM Journal. Vol. 5 (2),p. 192-196, ISSN 2217-8309, (2016)

[4] A. Romanová, P. Richnák,K. Porubanová, V. Bolek, "Application of Modern Information Technology in Innovation of Business Logistic Processes", AD ALTA : journal of interdisciplinary research. - Hradec Králové : MAGNANIMITAS, vol. 9, no. 1, s. 245-248, 2019 
[5] S. Kolarić, T. Mandičák, M. Vukomanović, P. Mesároš, "BIM training in construction management educational practices in Croatia and Slovakia", Creative Construction Conference, Ljubljana, Slovenia, June 30-July 03, pp. 1002-1009, 2018, https://doi.org/10.3311/ccc2018-130

[6] M, Galić, V. Venkrbec, F. Chmelik, I. Feinne, Z. Pučko and U. Klanšek, "Survey af accomplishments in BIM implementation in Croatia, The Czech republic, Germany and Slovenia", in Scientific paper, no. 15, 2017, https://doi.org/10.13167/2017.15.3

[7] S. Kolarić, D. Pavlović, M. Vukomanović, "Application of Building Information Modeling in Education", $12^{\text {th }}$ International Conference Organization, Technology and Management in Construction Conference Proceedings, Primošten., pp. 384-397, 2015

[8] S. Kolaric, M. Vukomanović, D. Stober and Z. Dolaček-Alduk, "Accessing educational approaches to Building Information Modeling (BIM) at construction management master studies in Croatia" in Tehnički vjesnik, vol. 24, no. 4, pp. 1255-1262, 2017, https://doi.org/10.17559/tv-20160922083031

[9] KR. G. Kreider, J.I. Messner, "The uses of BIM - classifying and selecting BIM uses", 2013

[10] J.M., Kamara, C.J. Anumba, "Collaborative systems and CE implementation in construction" Tommelein, I. D. (ed), Proceedings of the 3rd International Conference on Concurrent Engineering in Construction, Berkeley, CA, 1-2 July, pp. 87-98

[11] J. M. Kamara, Ch. J. Anumba, P. M. Carrillo, D. Nasreddin) Bouchlaghem, "Conceptual framework for live capture and reuse of project knowledge", Construction informatic digital library, Knowledge management in construction companies in the UK, vol. 24, No. 2, 2019, https://doi.org/10.1007/s00146-009-0202-9

[12] R. Bluentritt, R. Johnston, "Towards a Strategy for Knowledge Management", Technology Analysis and Strategic Management, 11 (3): 287-300.1988, https://doi.org/10.1080/095373299107366

[13] M. Renne, "Accounting for Knowledge Assets: Do we need a new Financial Statement?", International Journal of Technology Management, 18(5/6/7/8), 648-659, https://doi.org/10.1504/ijtm.1999.002794

[14] S.P. Wbb, "Knowledge Management: Linchpin of Change", The Association for Information Management (ASLIB), London, 1988, https://doi.org/10.4324/9781351227223

[15] R. Blumentritt, R. Johnston, "Towards a Strategy for Knowledge Management", Technology Analysis and Strategic Management, 11 (3): 287-300, 1999

[16] D. Bhargav, K. Lauri, "Collaborative knowledge management-A construction case study", Automation in Construction Vol.18, Issue 7, pp. 894-902, https://doi.org/10.1016/j.autcon.2009.03.015

[17] L. Kanapeckienea, A.Kaklauskasb, E.K. Zavadskasc, M.Seniutd, "Integrated knowledge management model and system for construction projects", Engineering Applications of Artificial Intelligence, Vol. 23, Issue 7, pp. 1200-1215, 2010, https://doi.org/10.1016/j.engappai.2010.01.030

[18] H.Ping Tserng Yu, Cheng Lin, "Developing an activity-based knowledge management system for contractors", Automation in Construction, Vol. 13, Issue 6, pp. 781-802, 2004, https://doi.org/10.1016/j.autcon.2004.05.003 